\title{
Papel da informação na área da qualidade: do fordismo ao capitalismo cognitivo'
}

\author{
The role of information in the area of quality: \\ From fordism to cognitive capitalism
}

Vanessa de Arruda JORGE²

Sarita ALBAGLI²

\section{Resumo}

Este artigo objetiva analisar o papel da informação nas principais mudanças ocorridas na área da qualidade, de modo associado às transformações no trabalho. Com base em pesquisa e análise bibliográfica, desenvolveu-se um quadro analítico, em que se apresenta uma periodização dando conta da evolução das mudanças da informação, ao longo das diferentes fases históricas da qualidade, em sua relação com as transformações no trabalho, desde o fordismo até o capitalismo cognitivo. Conclui-se que a informação ganhou maior destaque nos processos de qualidade a partir do momento em que ganha também importância o trabalho imaterial, cognitivo e linguístico, como gerador de valor e inovação, configurando-se como elemento chave para a qualidade.

Palavras-chave: Capitalismo cognitivo. Fordismo. Informação. Qualidade. Trabalho imaterial.

\begin{abstract}
The aim of the paper was to analyze the role of information that occurred during major changes in the area of quality associated with labor transformations. Based on research and analysis of the literature we developed an analytical framework to draw a timeline of the historical evolution of changes in the role and dynamics of information throughout different historical phases of quality and its relationship with labor transformations from Fordism to cognitive capitalism. It may be concluded that information became relevant in the process of quality after immaterial, cognitive and linguistic labor was considered an important and innovative asset, and therefore a key element in quality.
\end{abstract}

Keywords: Cognitive capitalism. Fordism. Information. Quality. Immaterial labor.

\section{Introdução}

Este artigo sintetiza os resultados de uma investigação sobre o papel da informação no âmbito das principais mudanças na área da qualidade, de modo associado às transformações ocorridas nos processos de trabalho, desde o capitalismo fordista até o chamado capitalismo cognitivo contemporâneo.

O artigo discute como, a partir da década 1970, as transformações nos processos produtivos e do

\footnotetext{
${ }^{1}$ Artigo elaborado a partir da dissertação de mestrado de V.A. JORGE, intitulada "Gestão da qualidade e trabalho imaterial: uma análise a partir da dinâmica informacional", Universidade Federal do Rio de Janeiro, 2012.

2 Universidade Federal do Rio de Janeiro, Instituto Brasileiro de Informação em Ciência e Tecnologia,Programa de Pós-Graduação em Ciência da Informação. R. Lauro Muller, 455, $4^{\circ}$ andar, Botafogo, RJ, Brasil. Correspondência para/Correspondence to:V.A. JORGE. E-mail:<vanessaajorge@gmail.com>

Recebido em 17/3/2014, reapresentado em 21/8/2014 e aceito para publicação em 26/9/2014
} 
trabalho afetaram diretamente as dinâmicas informacionais das organizações, particularmente na área da qualidade. É nesse período que o fordismo entra em crise. Empresas e demais organizações buscam soluções para lidar com o novo cenário, reestruturando sua rotina e inserindo novos conceitos em seus processos de trabalho. Flexibilidade, inovatividade, redução de custos e qualidade passam a fazer parte das estratégias adotadas, na tentativa de responder a esse novo quadro.

Elementos antes esquecidos ou privados a um seleto grupo na fábrica fordista passam a compor o centro da produção. A comunicação torna-se a principal ferramenta do processo de trabalho, ou ainda o próprio trabalho, agora comunicativo e linguístico, ligando trabalhadores entre si, produção e cliente, oferta e demanda, em uma relação multilateral de contínua combinação e recombinação de informações. A troca e a produção de informações, conhecimentos e saberes passam a constituir ingredientes centrais no desenvolvimento de produtos e serviços.

A entrada da comunicação diretamente na produção corresponde à valorização dos aspectos subjetivos, criativos, afetivos, comportamentais e cognitivos dos trabalhadores pós-fordistas, caracterizando o chamado trabalho imaterial. Este é baseado na produção de informações e de linguagens na cooperação e interação, que constituem o caráter crescentemente coletivo e social do trabalho.

No capitalismo cognitivo, a qualidade - que durante o período fordista estava focada no produto já pronto, como trabalho morto - ganha evidência. Evolui-se para o desenvolvimento de modelos de gestão que perpassam todo o processo de produção, envolvendo o controle da informação na administração dos recursos humanos, no controle de insumos necessários na produção, no gerenciamento de conhecimentos codificados etc.

\section{Procedimentos metodológicos}

Para realizar esta análise, foram efetuadas pesquisa e análise da literatura, caracterizando o panorama histórico das mudanças em três eixos temáticos e suas interseções: nos processos de trabalho a partir do período fordista; nas estratégias da qualidade das organizações; e no papel da informação nesse contexto.

Sem a pretensão de definir uma periodização das fases do capitalismo, para fins desta pesquisa, foram destacados três momentos marcantes da sua história, observando as transformações correspondentes no mundo do trabalho: o taylorista-fordista, o pós-fordista (considerando ser esta uma fase de transição) e o capitalismo contemporâneo, denominado por alguns autores como capitalismo informacional (Castells, 1999), novo espírito do capitalismo (Chiapello \& Boltanski, 2009) ou capitalismo cognitivo (Moulier Boutang, 2007), sendo este último conceito o utilizado neste trabalho.

Na área da qualidade, partiu-se da periodização proposta por Garvin (1992), naquilo que o autor chamou de eras da qualidade, quais sejam: inspeção; controle estatístico da qualidade; garantia da qualidade e gestão estratégica da qualidade. A partir dessa estruturação, procurou-se estabelecer a relação entre as grandes transformações no campo da qualidade e as transformações paradigmáticas do período capitalista correspondente.

A partir daí, procurou-se caracterizar o papel da informação em cada um desses momentos. Para tanto, buscaram-se no referencial teórico e empírico da ciência da informação abordagens tratando das questões informacionais no âmbito das organizações.

Foi então elaborado um quadro sintetizando as questões identificadas e analisadas na pesquisa, correlacionando os seguintes eixos de transformação: fase capitalista, fase da qualidade, objetivos da qualidade, características do trabalho com a qualidade, papel da informação na qualidade e principais atores informacionais. Ao final, é feita uma análise e discussão das evidências demonstradas nesse quadro.

\section{Discussão}

\section{Informação e qualidade}

No período fordista

O fordismo pode ser caracterizado como um regime de acumulação e modo de regulação que tem 
entre suas principais características a produção em massa e a organização produtiva em linhas de montagem automatizadas. Sua base está nas teorias de Taylor (1911) sobre uma "administração científica", que contribui para que Henry Ford construísse uma cadeia de montagem, multiplicando a produção de automóveis.

As informações geradas no controle do processo de trabalho constituíram elemento central para definir a melhor forma de se fazer uma tarefa. Segundo Coriat (2003), o trabalhador era, na visão de Taylor, um ser "pré-programável" e o taylorismo pode ser entendido então como o conjunto de gestos de produção, formalizado para o desenvolvimento do trabalho industrial, reduzindo o papel do saber do trabalhador e controlando seus passos elementares na realização do seu ofício. As práticas desenhadas por Taylor implicavam a divisão do trabalho, pela qual cada trabalhador tinha sua atividade desenhada para que melhor pudesse executá-la. Essa divisão mostrava claramente a distinção entre trabalho e gestão, bem como entre trabalho manual e intelectual, dentro da empresa ou organização.

A esse período do capitalismo (taylorismo-fordismo) correspondem três importantes fases na qualidade: inspeção, controle estatístico e garantia da qualidade, cada qual correspondendo a um determinado papel da informação no âmbito organizacional.

A era da inspeção está relacionada aos primórdios do período fordista. Antes desse período, os critérios de qualidade eram especificados pelo próprio artesão e sua pequena equipe de colaboradores (Garvin, 1992). A inspeção formal coincide com o desenvolvimento da produção em massa, pois a necessidade de padronização dos produtos exigia rigorosa verificação dos critérios estabelecidos por profissionais especializados e associados ao controle da qualidade. "O controle da qualidade se limitava à inspeção e às atividades restritas, como contagem, a classificação pela qualidade e os reparos" (Marshall Junior et al., 2005, p.20). Nesse período, as informações coletadas eram destinadas ao controle de possíveis erros em atividades específicas na produção.

A fase do controle estatístico da qualidade inicia-se com o aumento da quantidade e da complexidade dos produtos. Com as pesquisas empíricas realizadas nos Laboratórios Bell Telephone, na década de 1930, percebe-se a importância do controle voltado ao processo produtivo, via procedimentos estatísticos, logo informacionais. Observa-se então o esforço para obter "informações sistematizadas e perceber pontos críticos, oportunidades de melhoria e, principalmente, as variações ou flutuações devidas a causas normais (intrínsecas à natureza do processo) e as devidas a causas anormais ou específicas" (Marshall Junior et al., 2005, p.21).

Nesse período verifica-se um novo olhar sobre a qualidade e, particularmente, sobre o papel estratégico da informação nessa área. As informações adquiridas com o controle estatístico possibilitavam ganhos de lucratividade, à medida que auxiliavam na redução de perdas. A criação de grupos destinados a trocar informações e disseminar as práticas da qualidade permitiu o avanço desse campo em diversos países, aumentando as perspectivas de sua aplicação e passando também a envolver o próprio trabalhador. Com as possibilidades de lucro obtidas através da geração e apropriação de novos tipos de informações sobre o processo produtivo, verificam-se os primeiros incentivos em normalizar os processos, que levariam ao maior controle das informações do processo de trabalho.

Já no fim da Segunda Guerra Mundial, a qualidade passa a ser considerada uma disciplina, "com técnicas específicas e resultados efetivos, com profissionais especializados e bem caracterizados na especialidade" (Marshall Junior et al., 2005, p.22). Nesse período, pesquisadores da qualidade voltam sua atenção para o Japão com o objetivo de contribuir para a reconstrução da economia daquele país, que representava um campo de oportunidade para aplicação de novas ideias relacionadas à qualidade.

Dentre os pesquisadores que participaram da jornada no Japão destacam-se Deming e Juran. Deming (1990) volta suas análises ao uso de informações estatísticas e métodos administrativos para melhorar a qualidade. Focaliza sua atenção no processo produtivo (ao invés do produto) ao aperfeiçoar o ciclo PDCA (Plan, Do, Check, Action), tal como definido por Shewhart (1939), indicando que as ações corretivas da qualidade deveriam ser realizadas ao longo do processo produtivo. Para tanto, propõe um conjunto de princípios para transformação gerencial, atribuindo ao trabalhador uma nova importância no processo produtivo. Por sua vez, Juran e Gryna (1991) propõe, na década de 1950, um enfoque adminis- 
trativo e contínuo da qualidade, por meio de equipes por projeto, com base em uma trilogia de atividades de planejamento, controle e aperfeiçoamento da qualidade. Para alguns autores, inaugura-se assim a era do controle da qualidade, a partir de uma perspectiva"global e holística, abarcando todos os aspectos do gerenciamento e toda organização" (Marshall Junior et al., 2005, p.22).

É nesse contexto que se desenvolve o Total Quality Management (TQM), gestão da qualidade total, considerando a qualidade desde a fase do projeto de desenvolvimento e envolvendo todos os funcionários (de todos os níveis hierárquicos), fornecedores e clientes, bem como visando ao comprometimento, confiança recíproca e aperfeiçoamento das técnicas clássicas da qualidade.

Entretanto, em outros países, essa concepção não evolui no mesmo ritmo do Japão. A filosofia do TQM somente começa a ser amplamente incorporada nos processos produtivos a partir da década de 1970 (pós-fordismo). Com os estudos desenvolvidos naquele país, os pesquisadores da qualidade percebem a potência do trabalhador. Ele deixa de ser somente mão de obra da produção, para atuar como participante e corresponsável pela qualidade dos produtos. Ele ganha espaço para sugerir, criar, transformar, atividades que antes Ihe eram interditadas, passando a apropriar-se de algo que será entendido como um novo tipo de capital: o capital intangível.

Além da informação estatística, outros instrumentos foram mobilizados pelas estratégias de qualidade no fordismo: quantificação dos ganhos e custos da qualidade (a não qualidade traz consequências como retrabalho, refugo, devoluções etc.); controle total da qualidade (toda a empresa se envolve com a qualidade); engenharia da confiabilidade (a informação estatística não fica apenas restrita à fábrica, mas é utilizada também nos domínios do uso dos clientes); e zero defeito (metodologia que implicava a motivação e conscientização do "fazer certo na primeira vez").

Em relação ao papel da informação na qualidade, nessa fase, sua produção e seu uso estavam relacionados às ferramentas que serviam como suporte aos controles, como os gráficos e as estatísticas. Segundo Paladini (2000), um dos principais impactos da administração científica na qualidade foi o desenvolvimento dos gráficos de controle para medir a qualidade dos processos industriais. Essa informação era produzida no chão de fábrica e utilizada pelo grupo gestor, responsável pelo planejamento do trabalho. Não havia espaço para trocas de informações entre os trabalhadores, e aquela tarefa era desempenhada pelo grupo da gestão.

Desde o pós-Segunda Guerra, alguns dos precursores do campo da ciência da informação já vinham propondo novos métodos, práticas e ferramentas de recuperação da informação, ante a verificação das repercussões das mudanças técnicas na área, associadas à emergência da cibernética (Bush, 1945; Wiener, 1948; Shannon \& Weaver, 1949). Neste sentido, a experiência de Shannon e Weaver, (1949) nos laboratórios Bell, onde já eram desenvolvidos estudos sobre o controle da qualidade, com base em informações do processo de trabalho, contribuiu para o desenvolvimento da teoria matemática da comunicação.

Dessa perspectiva, as informações geradas no processo de trabalho eram sistematizadas por um grupo especial, e o trabalhador, o consumidor ou usuário não influenciavam nas interpretações das informações que geravam. O foco estava na busca de erros que pudessem ser percebidos com o controle das informações, com vistas ao desenvolvimento de soluções tecnológicas. A ideia de automatizar a recuperação da informação reduziria os erros decorrentes da ação humana e promoveria um aumento de produtividade (Oliveira \& Amaral, 1999).

\section{No período pós-fordista}

A partir da década de 1970, o fordismo entra em crise, dando início a uma fase de transição chamada por diversos autores de pós-fordismo. Nessa fase do capitalismo, elementos como a informação, a comunicação e o conhecimento ganham espaço na produção, provocando mudanças no campo do trabalho e da qualidade. O trabalho imaterial e o uso das Novas Tecnologias da Informação e Comunicação (NTIC) se expandem, transformando os modos de produção. Segundo Cocco (2000), o pós-fordismo é marcado por deslocamentos paradigmáticos, como a desterritorialização e a reorganização empresarial, surgindo assim novos fatores estratégicos que fazem parte de um outro ciclo no capita- 
lismo, particularmente uma nova relação entre produção e consumo. Para o autor,

o paradigma pós-fordista é, antes de mais nada, um paradigma social e qualifica-se pela integração produtiva dos consumidores como produtores, pois eles participam da produção, desde o momento da concepção, em dois níveis: pela integração em tempo real dos comportamentos de consumo; e pela proliferação disseminada dos atos criativos, lingüísticos e comunicativos (Cocco, 2000, p.87).

No período pós-fordista, a troca de informações entre empresa, fornecedores e clientes é considerada elemento essencial, tanto para se tentar conquistar o mercado consumidor, quanto para alcançar a inovação e a melhoria contínua de processos e produtos. As empresas percebem que a noção da qualidade não está somente no produto e, sim, em tudo que envolve a produção, desenvolvendo-se os sistemas de gestão da qualidade, que incluem o elemento humano e a informação que ele produz.

A qualidade ganha cunho estratégico, além de técnico. Valendo-se da experiência do Japão após a Segunda Guerra Mundial, especialistas redefinem os conceitos da área, ao perceber a"necessidade de ir além da simples conformidade com o projeto para se ter um produto de qualidade" (Cordeiro, 2004, p.22). Trata-se de não olhar somente para o produto pronto, mas para todo o processo produtivo. O processo de produção torna-se a fonte para transformações que agreguem valor ao produto.

As principais abordagens da qualidade nesse período são a gestão da qualidade total e a gestão estratégica da qualidade. A ideia de produzir em largas escalas (quantidade) é substituída pela ideia do just-in-time, em que a quantidade produzida corresponde à demanda do consumidor. Os investimentos em qualidade são considerados formas de conquistar novos clientes e, portanto, aumentar as vendas. A quantidade é agora uma possibilidade definida a partir da qualidade.

A reorganização produtiva do pós-fordismo leva ao desenvolvimento de um modelo de gestão da qualidade orientado para estratégias voltadas à promoção da inovatividade (incluindo "criatividade", "gestão participativa" e "simplicidade") e à normalização de ações visando a um maior controle das informações dos pro- cessos de trabalho. Em meio ao processo de globalização dos mercados, a gestão e a normatização internacional da qualidade passam a ser consideradas e observadas quando da comercialização de produtos e serviços.

Para além de seu uso no controle da rotina, auxiliando na confecção de diretrizes que visam à padronização e à produção em massa, a informação para qualidade, no pós-fordismo, torna-se insumo da produção e de sua conexão com as etapas de consumo. A troca de informações na cadeia produtiva possibilita a produção just-in-time e, também, um maior conhecimento sobre o cliente. Os trabalhadores são incentivados a registrar suas ações e a se comunicar, sendo os elementos linguísticos importantes para a nova filosofia da qualidade desse período, e o uso da informação deixa de ser exclusivo de um determinado grupo.

Nesse contexto, inserem-se as normas ISO da família 9000, que muitos consideram ter transformado "definitivamente o escopo da qualidade, consolidandoa em todos os pontos dos negócios" (Marshall Junior et al., 2005, p.27). Com os modelos de gestão da qualidade baseados nas normas ISO, a informação assume um novo papel, mediante o incentivo e facilitação do intercâmbio de informações entre os diversos atores, desde os produtores e trabalhadores até o consumidor.

Esse período coincide com o novo status dos estudos da gestão da informação nas organizações, ganhando terreno também os estudos sobre gestão do conhecimento. "Ao mesmo tempo em que se constitui no principal insumo das organizações, a informação também representa o meio de sincronizar as diversas funções, processos e setores de uma empresa, em busca de seus objetivos" (Moura, 1996, p.2). Nos anos 1980, projetam-se as teses de Takeuchi e Nonaka (1986), a respeito das relações entre conhecimento tácito e conhecimento explícito, em boa medida baseadas no trabalho desenvolvido por Polanyi (1966), da década de 1960.

No pós-fordismo, a gestão da informação e dos registros torna-se essencial para a qualidade, pois a informação servirá de base para a melhoria do processo de trabalho e, ao mesmo tempo, como insumo da produção e memória do conhecimento institucional. Os sistemas de gestão da qualidade são criados em torno de uma estrutura de documentos e informações alimen- 
tados pelos próprios trabalhadores. Conforme Valls (1998), o controle de documentos com informações atualizadas sobre as atividades dos trabalhadores torna-se conhecimento sobre os processos de trabalho e sua melhoria continua.

\section{No capitalismo cognitivo}

A terceira fase do capitalismo - o capitalismo cognitivo - inaugura-se a partir dos anos 1990 e se estende aos atuais. Segundo Fumagalli (2011), no capitalismo cognitivo, o modelo produtivo se apoia em uma estrutura em rede, dinâmica, e centrada mais na inovatividade (capacidade de inovar) do que na produtividade (entendida como quantidade de produtos iguais).

Com respeito à inovatividade, que é o que se vincula ao trabalho imaterial, o autor faz uma análise a partir de dois pontos de vista: o qualitativo e o quantitativo. Do ponto de vista qualitativo, o trabalho "maquínico", repetitivo, próprio do fordismo, perde centralidade relativamente ao trabalho do corpo e de sua subjetividade, especialmente a atividade cerebral e cognitiva, que assume o papel estratégico antes atribuído à maquinaria. Éa"bagagem" de experiências e subjetividades que se torna fonte do desejo e apropriação do capital, com vista à criação de inovações, novos mercados etc., daí ser chamada de produção biopolítica. Trata-se da "mobilização, cooperação e comunicação entre subjetividades, envolvendo afetos, corpos e linguagem, tornando produtiva a própria vida social, intelectual e afetiva" (Albagli, 2013, p.110). Do ponto de vista quantitativo, o problema é a dificuldade ou impossibilidade de calcular o valor da produção biopolítica das subjetividades, bem como o valor do cérebro humano. A produção material tem uma medida objetiva (quilos, horas etc.), ao passo não se pode dar uma medida à ideia, ao pensamento, ao imaterial (Fumagalli, 2011).

Em um mercado competitivo, as ideias de superação e novidade tornam-se essenciais à continuidade e ao crescimento dos negócios. Não se trata apenas de trazer ao mercado produtos novos, mas de garantir também que eles superem as expectativas quanto ao desempenho e qualidade, em relação a produtos anteriores. Nesse contexto, a qualidade ganha ainda nova expressão, porque responde também ao desejo de confiança e segurança dos consumidores. Ela se configura como um ativo intangível, que agrega valor a produtos e serviços e, portanto, como uma estratégia de aumento e renovação do consumo.

A implementação de uma norma ISO de gestão da qualidade é verificada com base no cumprimento de requisitos que especificam, não como a produção deve ocorrer, mas quais são as sistemáticas de avaliação, informação e documentação que devem ser criadas para que uma organização obtenha um certificado internacional. Os processos de trabalho e seus resultados devem ser registrados, para fins de controle de informação e conhecimento referentes à ação do trabalhador, em documentos conhecidos como "documentos da qualidade": manual da qualidade, procedimentos operacionais padrão, instruções de trabalho e registros da qualidade.

A obtenção do certificado está condicionada à comprovação do uso da norma, que se dá, principalmente, com a verificação dos documentos da qualidade, incluindo todos os registros. Toda essa mobilização acontece por meio de programas de envolvimento, cuja ideia central é de que cada trabalhador tem a missão de contribuir decisivamente para o alcance dos objetivos da organização e de atuar como agente transformador da qualidade, o que se torna o centro da gestão da qualidade (Paladini, 2000).

Dessa forma, a informação é fundamental nos modelos de gestão da qualidade no capitalismo cognitivo. A análise crítica para a melhoria contínua, que é o slogan utilizado para o incentivo à inovação no ambiente organizacional, dá-se principalmente através de análise dos resultados registrados quanto às ações do trabalhador. O incentivo ao registro das atividades do trabalhador cresce à medida que essas informações são consideradas parte de um conhecimento tácito, transformado em conhecimento institucional. Daí a recente ênfase na gestão das informações e documentos, bem como na gestão do conhecimento.

Na literatura da área da ciência da informação, há esforços no sentido de estabelecer suas relações com a gestão do conhecimento organizacional, como, por exemplo, os estudos de Kebede (2010). Para além da tecnologia ou do controle, a proposta intrínseca nas 
práticas da gestão da qualidade - normas ISO e programas de excelência em gestão - é a gestão do conhecimento institucional. Especificamente a sinergia da gestão da qualidade e da gestão do conhecimento pode ser observada em diversos aspectos, como na padronização e documentação dos processos de trabalho, na elaboração de documentos da qualidade, nas trocas em reuniões de trabalho, brainstorming, treinamentos etc. (Valls, 2004). Conforme Brito e Vergueiro (2011), a gestão da qualidade pode servir de base e apoiar a gestão do conhecimento. Dessa forma, o papel da informação no atual período é visto como vital para a sobrevivência e o funcionamento das organizações, principalmente aquelas com modelos de gestão da qualidade implementados.

\section{Resultados}

A partir da pesquisa realizada, foi possível traçar um panorama das transformações da noção da qualidade e do papel da informação, relacionando-as às principais mudanças na dinâmica produtiva e no papel do trabalho, em diferentes momentos do capitalismo, conforme sintetizado no Quadro 1.

É importante destacar que, quando se refere a "novas fases", isso não significa dizer que elementos típicos da fase anterior deixaram totalmente de existir. No caso do controle e gestão da qualidade, que evolui e ganha destaque junto com as transformações do capitalismo industrial em capitalismo cognitivo, passando pelo pós-fordismo, a cada fase são acrescidas novas significações e papéis à informação, com o desenvolvimento de instrumentos e ferramentas para auxiliar na gestão, de modo que o trabalho imaterial e, logo, informacional assume papel central.

No que diz respeito ao papel da informação, pode-se afirmar que, no fordismo, o usuário da informação não era o seu produtor ou seus pares. A informação gerada no processo de trabalho era somente acessada ou utilizada por grupos específicos, constituídos pelo inspetor e pelo grupo de planejamento. Seu papel era de verificação e planejamento da produção para evitar falhas ou erros nas mercadorias produzidas, permitindo a padronização e evitando prejuízos.

No pós-fordismo, o papel da informação na qualidade se modifica e torna-se insumo dos processos de trabalho, permitindo os fluxos informacionais entre produtor e consumidor (just-in-time). A equipe da qualidade fica responsável por centralizar e criar nos usos para informação, de modo que esta se transforme em valor para a organização.

Quadro 1. Informação, qualidade e trabalho: evolução histórica.

\begin{tabular}{|c|c|c|c|c|c|}
\hline $\begin{array}{l}\text { Fase } \\
\text { capitalista }\end{array}$ & $\begin{array}{c}\text { Fase da } \\
\text { qualidade }\end{array}$ & $\begin{array}{l}\text { Objetivos da } \\
\text { qualidade }\end{array}$ & $\begin{array}{l}\text { Características do } \\
\text { trabalho X qualidade }\end{array}$ & $\begin{array}{c}\text { Papel da informação } \\
\text { na qualidade }\end{array}$ & $\begin{array}{l}\text { Principais atores } \\
\text { informacionais }\end{array}$ \\
\hline Fordista & $\begin{array}{l}\text { Inspeção; controle es- } \\
\text { tatístico da qualidade; } \\
\text { garantia da qualidade. }\end{array}$ & $\begin{array}{l}\text { Foco no produto e na } \\
\text { quantidade, padroni- } \\
\text { zação da produção em } \\
\text { massa; redução de } \\
\text { perdas; lucratividade. }\end{array}$ & $\begin{array}{l}\text { Trabalho industrial, com } \\
\text { atividades de contagem, } \\
\text { classificação e reparos; } \\
\text { quantificação dos custos; } \\
\text { controle total da qualidade; } \\
\text { engenharia da confiabili- } \\
\text { dade; zero defeito. }\end{array}$ & $\begin{array}{l}\text { Informações sistemati- } \\
\text { zadas para controle es- } \\
\text { tatístico; gráfico de con- } \\
\text { troles; normalização de } \\
\text { atividades. }\end{array}$ & $\begin{array}{l}\text { Inspetor; grupo de } \\
\text { planejamento do tra- } \\
\text { balho. }\end{array}$ \\
\hline Pós-fordista & $\begin{array}{l}\text { Gestão da qualidade } \\
\text { total (TQM) e gestão es- } \\
\text { tratégica da qualidade. }\end{array}$ & $\begin{array}{l}\text { Foco na produtivida- } \\
\text { de; produção just-in- } \\
\text { time. }\end{array}$ & $\begin{array}{l}\text { Criatividade, gestão partici- } \\
\text { pativa e simplicidade. }\end{array}$ & $\begin{array}{l}\text { Informação como insu- } \\
\text { mo da produção. }\end{array}$ & Equipe da qualidade. \\
\hline $\begin{array}{l}\text { Capitalismo } \\
\text { cognitivo }\end{array}$ & $\begin{array}{l}\text { Gestão da qualidade } \\
\text { (ISO) e excelência em- } \\
\text { presarial (prêmios da } \\
\text { qualidade). }\end{array}$ & $\begin{array}{l}\text { Foco na inovatividade, } \\
\text { na rastreabilidade dos } \\
\text { processos produtivose } \\
\text { na produção de conhe- } \\
\text { cimento. }\end{array}$ & $\begin{array}{l}\text { Trabalho imaterial em que } \\
\text { se mobiliza a subjetividade } \\
\text { (cérebro, sentimentos, de- } \\
\text { sejos e relações). }\end{array}$ & $\begin{array}{l}\text { Informação para ava- } \\
\text { liação da conformidade, } \\
\text { análise crítica, melhoria } \\
\text { contínua e gestão do } \\
\text { conhecimento institu- } \\
\text { cional. }\end{array}$ & $\begin{array}{l}\text { Trabalhadores, forne- } \\
\text { cedores e consumi- } \\
\text { dores. }\end{array}$ \\
\hline
\end{tabular}

Fonte: Elaborado pelos autores (2014). 
Por fim, no capitalismo cognitivo, informação e conhecimento são essenciais para a sobrevivência dos negócios. A gestão da qualidade se apresenta nas normas ISO e prêmios de excelência em gestão, que buscam uma apropriação de elementos imaterias para a promoção da inovatividade e a gestão do conhecimento institucional.

\section{Conclusão}

Com as transformações do capitalismo e do trabalho, ocorridas principalmente após os anos 1970, surgem novos modelos de gestão estratégica que visam controlar diversos elementos do processo produtivo, especialmente o trabalho imaterial.

No decorrer das fases capitalistas consideradas neste estudo, constatou-se que a qualidade deixou de ter foco estrito no produto (trabalho morto) para inserirse nas diferentes etapas do processo de trabalho (trabalho vivo). Disso derivou o desenvolvimento de estratégias para apropriação do chamado trabalho imaterial ou biopolítico. A qualidade, que até então era tratada como elemento ex post da produção, passa a integrar todo o processo produtivo. Dessa forma, os discursos e estratégias da gestão da qualidade passam a incorporar o envolvimento dos trabalhadores no sentido de mobilizar sua subjetividade em favor da qualidade, registrar sua expe- riência e codificar seu conhecimento, com vistas a obter informações, em todo o processo produtivo, incluindo a relação com o consumidor.

Nesse cenário, a informação assume novo papel na qualidade, envolvendo novas formas de produção e uso. A partir do momento em que o trabalhador é visto como agente transformador dos processos de produção e inovação, sendo chamado a promover melhorias contínuas, a realizar a análise crítica de seu próprio trabalho, a possibilitar a divulgação de suas ações e processos de inovação, ele passa a ser visto também como um produtor estratégico de informações para a qualidade e a inovatividade organizacional.

Os rumos e papéis que a informação desempenha no decorrer do tempo na área da qualidade abrem espaço para atuação específica dos profissionais da informação nas organizações. Nesse aspecto, a ciência da informação tem vasto campo de estudos e análises nas linhas de pesquisas que procuram acompanhar as mudanças na produção e o papel da informação nesse cenário.

Confirmou-se assim a hipótese de que, no capitalismo cognitivo, a informação passou a desempenhar novo papel, no contexto das mudanças na noção de qualidade, nas estratégias de qualidade e no próprio trabalho, tornando-se um dos eixos de reorganização do novo modelo econômico.

\section{Referências}

Albagli, S. Informação, saber vivo e trabalho imaterial. In: Albagli, S. (Org.). Fronteiras da ciência da informação. Brasília: IBICT, 2013. p.107-126.

Brito, G.F.; Vergueiro, W.C.S. Qualidade centrada nos clientes e conhecimento organizacional: aplicação em serviços de informação. Revista Percursos, v.12, n.2, p.5-21, 2011.

Bush, V. As we may think. Atlantic Monthly, v.176, n.1, p.101-108, 1945.

Castells, M. A sociedade em rede. São Paulo: Paz e terra, 1999.

Chiapello, E.; Boltanski, L. O novo espírito do capitalismo. São Paulo: Martins Fontes, 2009.

Cocco, G.M. Trabalho e cidadania: produção e direitos na era da globalização. São Paulo: Editora Cortez, 2000.

Cordeiro, J.V.B.M. Reflexões sobre a gestão da qualidade total: fim de mais um modismo ou incorporação do conceito por meio de novas ferramentas de gestão? Revista da $F A E$, v.7, n.1, p.19-33, 2004.

Coriat, B. El tallery el cronometro: ensayo sobre el taylorismo, el fordismo y la producción en masa. Madrid: Siglo XXI, 2003.
Deming, W.E. Qualidade: a revolução da administração. Rio de Janeiro: Marques-Saraiva, 1990.

Fumagalli, A. À saída do capital à crise é a privatização da vida. Jornal Diagonal, 17 jan. 2011. Disponível em: <http://www. diarioliberdade.org/index.php?option=com_content\& view=article\&id=11198:andrea-fumagalli-a-saida-do-capitala-crise-e-a-privatizacao-total-da-vida\&catid=99:batalha-deideias\&ltemid=113>. Acesso em: 28 out. 2011.

Garvin, D.A. Gerenciando a qualidade: a visão estratégica e competitiva. Rio de Janeiro: Qualitymark, 1992.

Juran, J.M.; Gryna, F.M. Controle da qualidade: conceitos, políticas e filosofia da qualidade. São Paulo: Makron Books, 1991.

Kebede, G. Knowledge management: An information science perspective. International Journal of Information Management, v.30, n.5, p.416-424, 2010.

Marshall Junior, I. et al. Gestão da qualidade. Rio de Janeiro: FGV, 2005. 
Moulier Boutang, Y. Le capitalisme cognitif. Paris: Éditions Amsterdam, 2007.

Moura, L.R. Informação: a essência da qualidade. Ciência da Informação, v.25, n.1, p.1-10, 1996.

Oliveira, J.N.; Amaral, L. O papel da qualidade da informação nos sistemas de informação. In.: Conferência Especializada em Sistemas e Tecnologias de Informação, Lisboa, 1999. Disponível em <http://repositorium.sdum.uminho.pt/handle/1822/ 2183>. Acesso em: 11 ago. 2014.

Paladini, E.P. Gestão da qualidade: teoria e prática. São Paulo: Atlas, 2000.

Polanyi, M. The tacit dimension. Chicago: University of Chicago Press, 1966.

Shannon, C.; Weaver, W. The mathematical theory of communication. Chicago: University of Illinois Press, 1949.
Shewhart, W.A. Statistical method from the viewpoint of quality control. Washington: Department of Agriculture, 1939.

Takeuchi, H.; Nonaka, I. The new new product development game. Harvard Business Review, n.64, p.285-305, 1986.

Taylor, F.W. Principles of scientific management. New York: Harper \& Row, 1911.

Valls, V.M. O profissional da informação no sistema da qualidade da empresa: um novo espaço para atuação com ênfase no controle de documentos e registros de qualidade. 1998. Dissertação (Mestrado) - Escola de Comunicações e Artes, Universidade de São Paulo, São Paulo, 1998.

Valls, V.M. A sinergia entre a gestão da qualidade e do conhecimento. Banas Qualidade, v.151, n.14, p.38-39, 2004.

Wiener, N. Cybernetics or the control and communication in the animal and the machine. Cambridge: MIT Press, 1948. 

